\title{
Thermal degradation and stability of wood particle composites deployed as decorative components
}

\author{
Dana Luca Motoc ${ }^{*}$, Santiago Ferrándiz Bou², and Adrian Petru Pop ${ }^{3}$ \\ ${ }^{1}$ Transilvania University of Brasov, Automotive and Transport Department, 500107 Bd. Eroilor, Romania \\ ${ }^{2}$ Polytechnic University of Valencia, Mechanical and Material Engineering Department, 03801 Plaza Ferrandiz-Carbonell, Spain \\ ${ }^{3}$ University of Oradea, Mechatronics Department, 410087 Str. Universitatii, Romania
}

\begin{abstract}
The contribution aims to design, deliver and debate on thermal degradation and thermal stability of several wood/PP composite materials. The wood polymer-based composites (n. WPCs) were manufactured through injection moulding by deploying various wood species under $10 \%$ and $40 \%$ weight fraction within the thermoplastic matrix. Thermal degradation of WPC specimens revealed similarities in characteristics, small discrepancies in the degradation temperatures but higher contents in the char formation, between $10 \%$ to $35 \%$ with wood content increase.
\end{abstract}

\section{Introduction}

Wood particles reinforced plastic composites (WPCs) timely captured the headlines of publishing literature proven their extensive studies since, firstly, issued. A closer reading reveals the systemic approaches on the combination of reduced manufacturing cost, overall material performance, environmental friendly and recyclable attributes [1-4]. These are imperative with composite industry and other key stakeholders focused to fulfil customer demands, face an increased competition and drive economic development and innovation.

Furthermore, low or high-density polyethylene (HDPE) and polypropylene (PP) appear to prevail within the broad range of common thermoplastics used for WPCs manufacturing irrespective the incompatibility issues shown at wood reinforcements/polymer interface. Solutions were seeking in terms of various coupling agents, individual or combined chemical treatments of wood reinforcements prior to their embodiment to improve interfacial adhesion, homogeneity, processability and decrease water absorption.

A relatively large database of research papers is covering the aforementioned subject, generally, while the works of Danyady (2007, 2010), Matini Behzad (2012) or Csizmadia (2013) and their co-authors can be traced in relation to the constitutive of herein paper, particularly [58]. Their findings shown that irrespective of the technique used on interface adhesion properties of interest resulted dissimilarly. Moreover, they argued on targeted properties invariability with the coupling agent amount and need for constitutive optimization in order to manage the overall materials' performance.

In addition, interfacial inconsistencies were shown to highly impact the mechanical, thermal stability, weatherability or flammability performances. Tangible evidence on prior listed can be identified with the works of Srubar et al. (2012), Zhang et al. (2012), Liqing et al. (2013) or Soares (2013) and co-authors on opposite with use of additives, flame retardant materials or other surface conditioning techniques [9-11]. Admittedly, the resulted quantitative values favour on the addressed properties' enhancement.

Influence of wood species and content while engineering the overall material properties were issues tackled by researchers and accounted as primary influencing factors. Thus, works of Fabiyi or Nourbakhsh and their co-authors (2010), Bouza et al. (2011), Jeamtrakull et al. (2012) and Thumm (2013) can be traced as contribution approaching the subject [12-16].

Further literature insights enable tracks in conjunction with mechanical performances and thermal stability of composite materials out of thermoplastic to balance the manufacturing costs, environmental issues and material properties.

The major drawbacks impeding the widespread use of WPC in structural applications can be related to the limited information on their thermal stability properties. Contributions of Yang (2005), Chaharmahali (2010), Cui (2010) and Singh (2010) or Pengfei (2011) and co-authors it can be traced in relation to previous [17-21].

Their findings' emphasis a slightly decrease on both thermal stability and expansion properties as the lignocellulosic content increased, with or without use of additives to improve compatibility of composite components, irrespective of the experimental settings (e.g. controlled atmosphere, heating rate, etc.). Moreover, with respect to the mechanical performances, increased values were reported in comparison with an unmodified system used as reference.

Hence, in the line with above, the objective of the present work focused on the effect of wood constituents

\footnotetext{
* Corresponding author: danaluca@unitbv.ro
} 
and content on thermal degradation and thermal stability of several wood/PP composite materials.

\section{Experimental research}

\subsection{Material selection and specimen preparation}

Wood species such as beech (lat. fagus sylvatica), oak (lat. quercus robur), sapele (lat. E. cylindricum), pine (lat. pinum) and a mixture of previous as agglomerate (n. wt.\% of individual constitutive were not tackled as an issue for further debates) were reinforced in different weight fraction within the thermoplastic matrix, $10 \mathrm{wt} . \%$ and 40 wt.\%, respectively.

Prior injection moulding into test specimens by aid of a Meteor 270/75 injection machine (Mateu\& Sole ${ }^{\circledR}$, Spain) at $185{ }^{\circ} \mathrm{C}$, all wood particles were subjected to a moisture removal process within a controlled temperature chamber at $85^{\circ} \mathrm{C}$ for $24 \mathrm{~h}$.

\subsection{Material testing procedure}

\subsubsection{Thermogravimetric analysis (TGA)}

Experimental research on thermal degradation of wood particle reinforced composites was performed using a Netzsch TG/DTG thermogravimetric analyser called STA 449 F3 Jupiter.

The measurements were carried out according to the general procedures outlined by DIN ISO 11358-1:201410 standard followed by deployment of ASTM E113108:2014 for compositional analysis particular to thermogravimetric technique.

The TGA system enables detection of specimens' mass variation of $1 \mu \mathrm{g}$ as a function of temperature. Wood plastic composite samples were subjected to pyrolysis in nitrogen environment $(20 \mathrm{ml} / \mathrm{min}$ flow) to a maximum temperature of $650{ }^{\circ} \mathrm{C}$ at a linear heating rate of $10 \mathrm{~K} / \mathrm{min}$ inside to an alumina sample holder.

Isothermals lasting of $5 \mathrm{~min}$ followed by dynamic cooling step at identical rate of $10{ }^{\circ} \mathrm{C} / \mathrm{min}$ were discarded from data processing proven their deployment only for measuring completeness.

For every WPC specimen the weight change (\%) and degradation speed $(\% / \mathrm{min})$ curves revealing the main peaks were managed by Netzsch Proteus Thermal Analyzer software. Supplementary, thermal degradation of PP specimen was also recorded to help the comparison purpose.

\subsubsection{Dilatometry (DIL)}

Thermal expansion was monitored using a Netzsch DIL 402 PC pushrod dilatometer. Combined DIN 510451:2005-08 and ASTM E228:1995 standard basic rules were deployed to assess the coefficients of thermal expansion (i.e. CTE) of wood plastic composite samples.

Thermal strain fields were recorded in static air atmosphere to a maximum temperature of $200{ }^{\circ} \mathrm{C}$ at a linear heating rate of $1{ }^{\circ} \mathrm{C} / \mathrm{min}$ by simple laying the wood composites on two fused silica sample holders. By aid of a thermocouple, records on samples' dimensional changes as function of temperature were enabled.

\section{Results and discussions}

The thermal decomposition characteristics of WPC specimens herein were examined by means of TG/DTG. The thermogravimetric parameters retrieved for all WPC composite samples are summarized in Table 1.

In Fig. 1 and Fig. 2 were plotted the typical curves for mass loss (\%) while in Fig. 3 and Fig. 4 plots of degradation speed $(\% / \mathrm{min})$ for individual specimens in accordance with their wt. $\%$ can be identified.

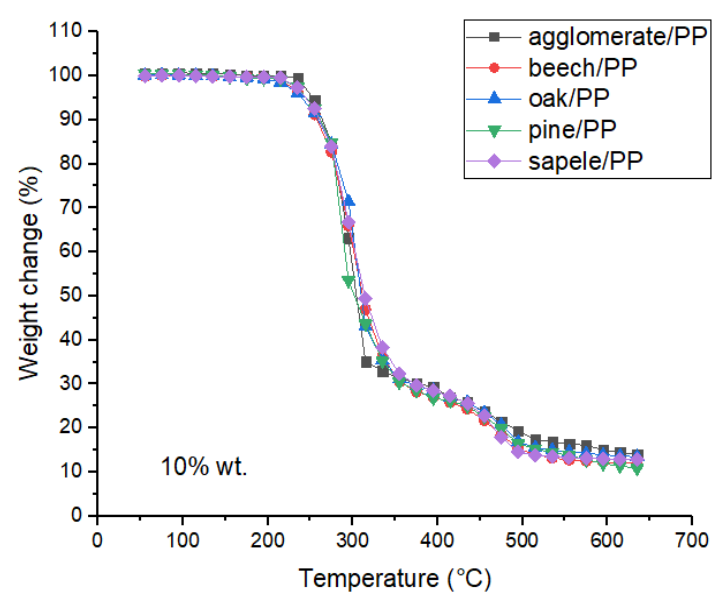

Fig. 1. Weight change over temperature range - $10 \mathrm{wt} . \% \mathrm{WPC}$

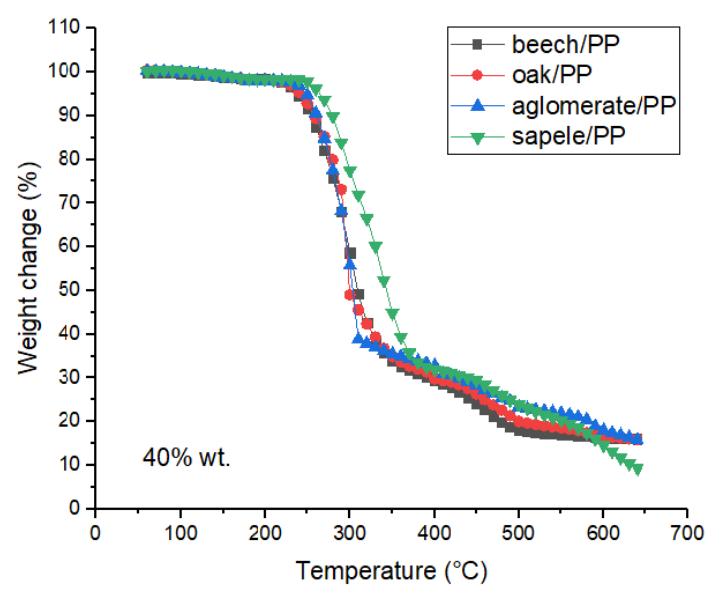

Fig. 2. Weight change over temperature range $-40 \mathrm{wt} . \% \mathrm{WPC}$

As it can be seen form Fig. 1 and Fig. 2 retrieved on WPCs specimens subjected to pyrolysis, two regions can be clearly identified. First, one can observe a specimens' slight weight loss occurring within $50^{\circ} \mathrm{C}$ up to $200^{\circ} \mathrm{C}$ that can be assigned mainly to thermal decomposition of PP and further to water evaporation and residues from manufacturing procedure (e.g. lubricants, residues from former deployment, etc.). 


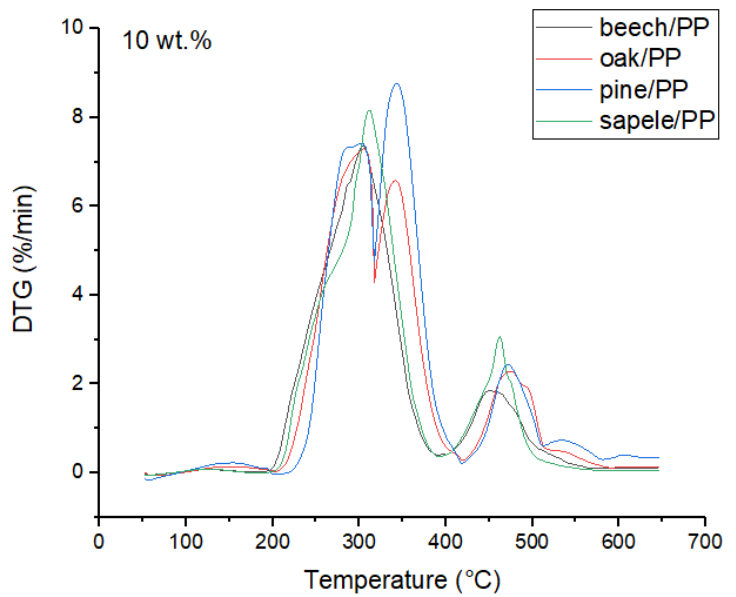

Fig. 3. Representative DTG curves for $10 \mathrm{wt} . \%$ wood/PP

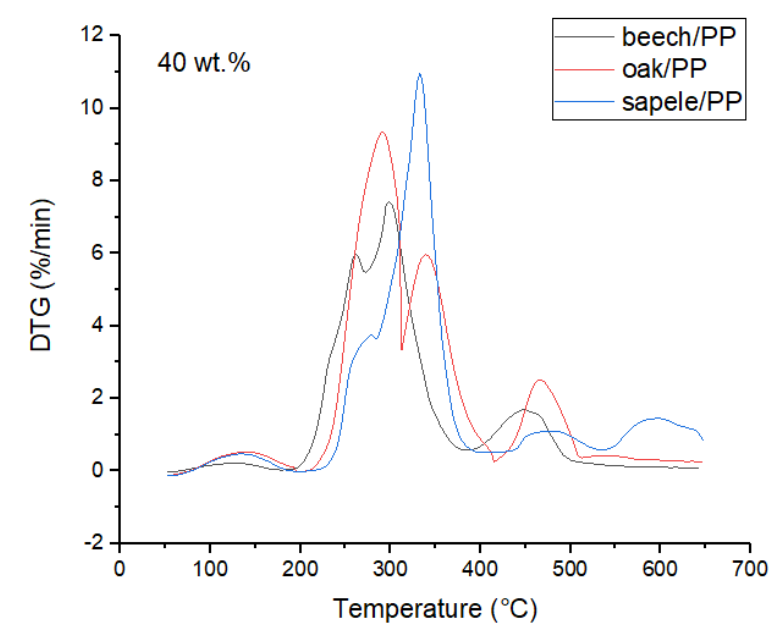

Fig. 4. Representative DTG curves for $40 \mathrm{wt} . \%$ wood/PP

Next, the second region, associated with temperature variation from $200{ }^{\circ} \mathrm{C}$ up to $650{ }^{\circ} \mathrm{C}$, corresponds to the active pyrolysis due to the thermal degradation of wood particles embedded within. With respect to the latter, three principal components namely hemicellulose, cellulose and lignin are sought to degrade within above temperature range as it can be seen in Fig. 5 for a 10\% wt. sapele/PP sample.

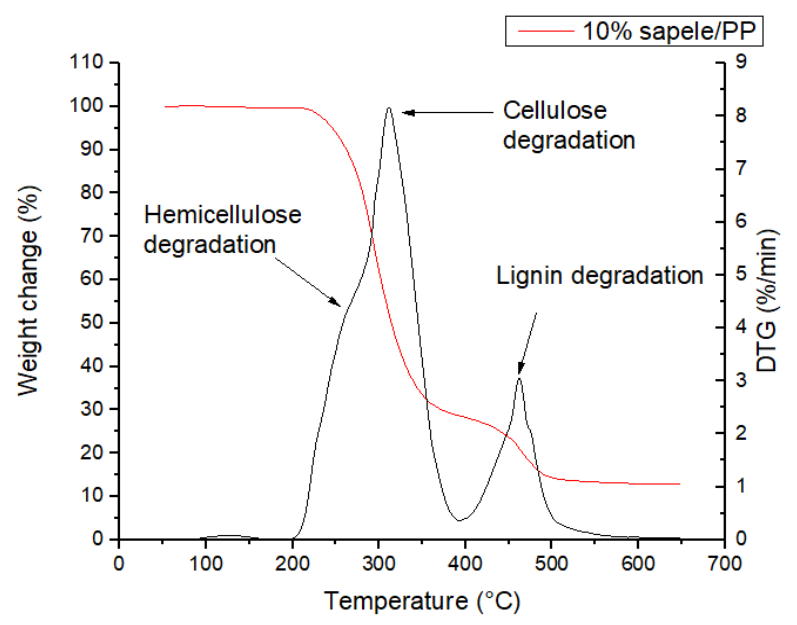

Fig. 5. TG/DTG curves for the $10 \mathrm{wt} . \%$ sapele/PP specimens
The first shoulder highlights the hemicellulose degradation from $200{ }^{\circ} \mathrm{C}$ up to $275^{\circ} \mathrm{C}$, while cellulose degradation follows next up to $400{ }^{\circ} \mathrm{C}$.

Furthermore, the principal decomposition behaviour is not changed from wood species from other accounting the same weight fraction but one can see a shift in the weight loss with increasing wood content, especially for sapele/PP specimens (see Fig. 2).

It is well acknowledged that wood consist of different complicated high molecular compounds, namely cellulose (33-50\% of absolute dry mass), lignin (20-30\%) and hemicellulose (14-27\%). Both cellulose and hemicellulose are natural polymers while lignin is a natural aromatic polymer that accounts for shape and size changes resistance of wood cells [22]. Decomposition of above components happen after the moisture evaporation, beyond $200{ }^{\circ} \mathrm{C}$.

In relation with the derivative thermogravimetric curves (DTG) in figures 3 and 4, respectively, the curves main peaks differ with respect to their magnitude while switching from $10 \mathrm{wt} . \%$ to $40 \mathrm{wt} . \%$ reinforcements in all wood species under debate.

Lower particles content within the PP matrix seem to provide enhanced thermal stability during the cellulose degradation compared with an increased reinforcement content.

Table 1. TGA and DTA results of WPC samples

\begin{tabular}{|l|c|c|c|c|c|}
\hline Sample & $\begin{array}{c}\mathbf{T}_{-5 \%} \\
{ }^{\circ} \mathbf{C}\end{array}$ & $\begin{array}{c}\mathbf{T}_{-50 \%} \\
{ }^{\circ} \mathbf{C}\end{array}$ & $\begin{array}{c}\mathbf{T}_{\mathbf{m a x}} \\
{ }^{\circ} \mathbf{C}\end{array}$ & $\begin{array}{c}\mathbf{D T A}_{\text {pea }} \\
\mathbf{k} \\
{ }^{\circ} \mathbf{C}\end{array}$ & $\begin{array}{c}\text { Res. } \\
\mathbf{m a s s} \\
\mathbf{\%}\end{array}$ \\
\hline Agg./PP & $\begin{array}{c}253 . \\
3\end{array}$ & $\begin{array}{c}302 . \\
9\end{array}$ & $\begin{array}{c}426 . \\
9\end{array}$ & 389.1 & $\begin{array}{c}13.6 \\
2\end{array}$ \\
\hline Beech/PP & 241. & 311. & 454. & 455.2 & 11.7 \\
& 5 & 1 & 8 & & 6 \\
\hline Oak/PP & 240. & 301. & 455. & 456.7 & 13.2 \\
& 8 & 8 & 4 & & 8 \\
\hline Pine/PP & 246. & 302. & 455. & 448.9 & 10.3 \\
& 7 & 0 & 2 & & 2 \\
\hline Sapele/P & 245. & 314. & 455. & 461.0 & 12.7 \\
P & 9 & 2 & 8 & & 8 \\
\hline \multicolumn{7}{|c|}{40 wt. $\%$} \\
\hline Agg./PP & 247. & 303. & 427. & 385.8 & 15.0 \\
& 6 & 6 & 0 & & 9 \\
\hline Beech/PP & 237. & 309. & 451. & 453.4 & 16.0 \\
& 6 & 2 & 2 & & 0 \\
\hline Oak/PP & 230. & 295. & 456. & 449.5 & 15.5 \\
& 5 & 1 & 5 & & 7 \\
\hline Pine/PP & 234. & 265. & 449. & 318.9 & 10.5 \\
& 1 & 0 & 1 & & \\
\hline Sapele/P & 237. & 315. & 446. & 410.3 & 6.39 \\
P & 8 & 6 & 2 & & \\
\hline
\end{tabular}

Supplementary, as it can be seen in the correspondingly graphs, a higher content of wood particles it leads to a degradation speed curve widening.

The last stage of the thermal decomposition is char combustion, that differ from wood species to another. Curves analysis reveal that char combustion occurs in the temperature range $450{ }^{\circ} \mathrm{C}-550{ }^{\circ} \mathrm{C}$. Accounting the 
decomposition processes holding under air, this process is considered to be an exothermic process.

Supplementary, is it well known that temperature and particle size of reinforcement influence the morphology of the char. It is beyond the purpose of herein article to debate on above, however it should be mentioned that the heating rate imposed to the measurements input was selected to surpass the impediment due to the particle size influence occurring at low heating rates.

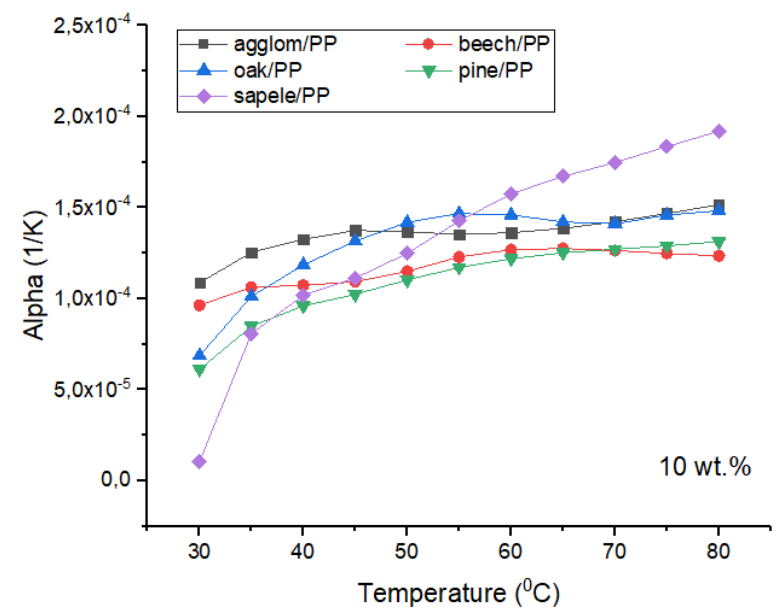

Fig. 6. Linear coefficient of thermal expansion with temperature range for $10 \mathrm{wt} . \%$ wood particles

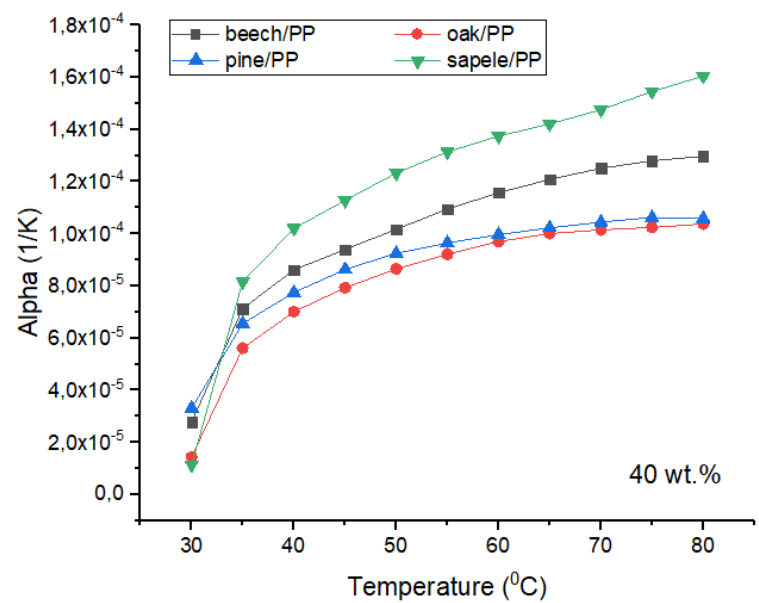

Fig. 7. Linear coefficient of thermal expansion with temperature range for $40 \mathrm{wt} . \%$ wood particles

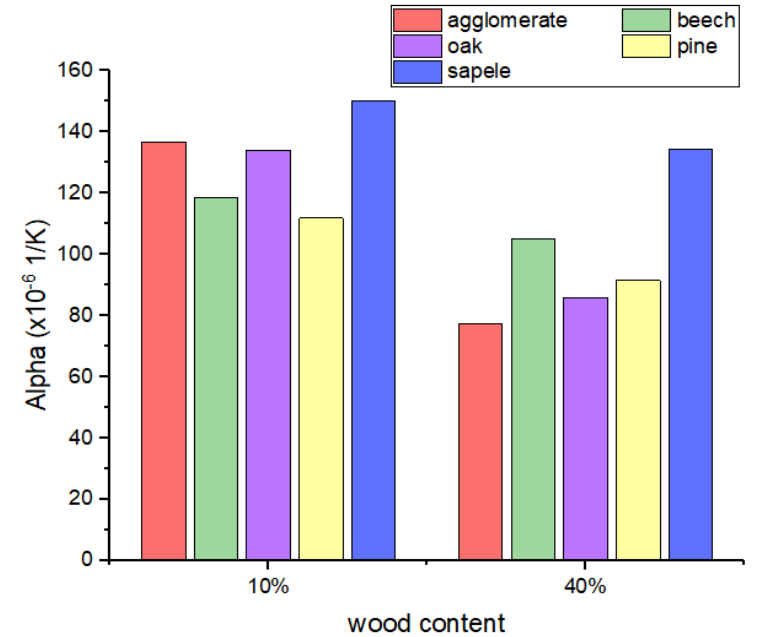

Fig. 8. Overall coefficient of thermal expansion with 10 wt.\% and $40 \mathrm{wt} . \%$ wood particle content

With respect to residual mass on the wood particle composites herein, from the above table it can be sized relatively small differences from one species to another, or with increasing wood content.

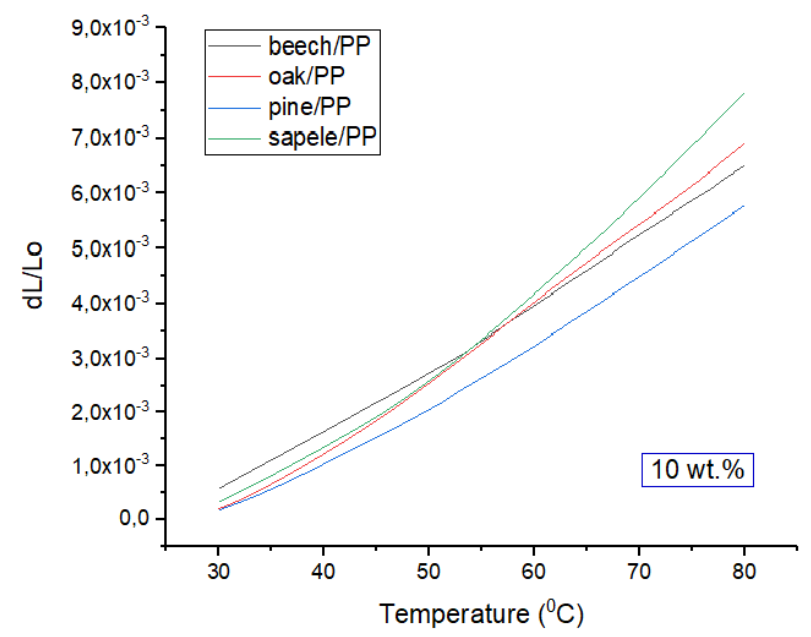

Fig. 9 Thermal stress field developed within 10 wt. \% wood particles samples

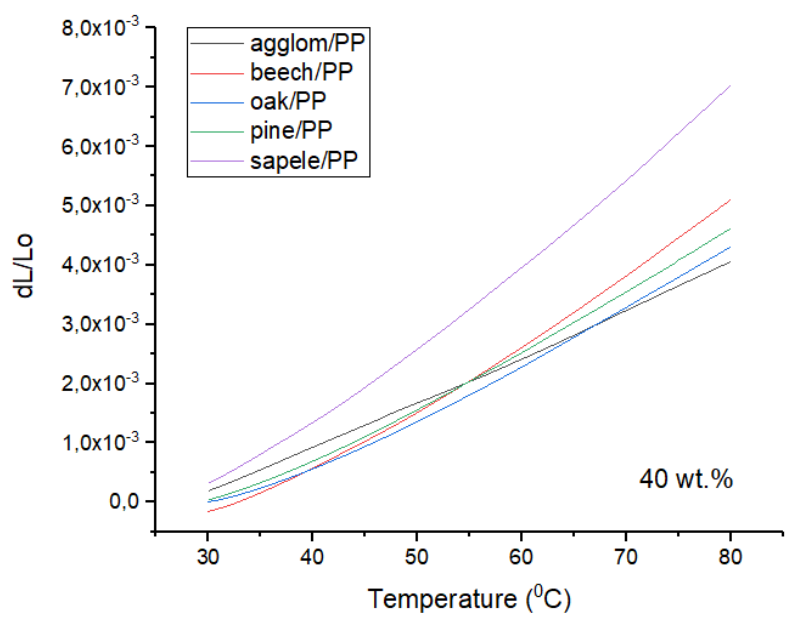

Fig. 10 Thermal stress field developed within 40 wt. \% wood particles samples 
In addition, a shift to lower temperatures occur in relation to the second peak that corresponds to the lignin degradation, both on TG curves and their first derivative (i.e. degradation speed).

The temperatures $\mathrm{T}_{-5 \%}$ and $\mathrm{T}_{-50 \%}$ of $5 \%$ and $50 \%$ weight loss, respectively, along with the temperature of maximum decomposition rate $\left(\mathrm{T}_{\max }\right)$ were listed within Table 1 for all wood/PP composites under discussion.

A closer look into the values provided on individual wood particle content category, reveal differences that cannot be accounted to exhibit an increasing or decreasing trend, but different. These differences can be regraded to the decomposition of cellulose backbone, that is particular to the wood species accounted with the study.

Thermal stability in WPCs specimens can be monitored by heating up within a controlled atmosphere the samples. As expected, the wood particle content as well as woos species have a great contribution on the evolution over selected temperature range of the linear coefficient of thermal expansion (n. CTE) on individual samples. These can be sized from graphical representations from Fig. 6 to Fig. 8, on different wood particles content.

Thus, samples with 10 wt.\% wood particle content within their PP matrix, exhibit CTE values experiencing approximatively a linear variation over the temperature range. The $\mathrm{PP}$ expansivity is dominant in the overall CTE variation with temperature.

Moreover, irrespective the wood species, the CTE values are very close in case of agglomerate, oak and sapele composites and slightly lower on the other samples.

Next, an increase in the wood content is impeding high expansivity as encountered in the $10 \mathrm{wt} . \%$ WPCs. Pine, oak and agglomerate reinforced thermoplastics are experiencing the highest decrease in their overall CTE.

Overall thermal stress field developed within the herein wood particle reinforced PP were plotted on Fig. 9 and Fig. 10. The values were collected from the second thermal cycle runs applied upon the wood particle reinforced PP plastic.

Data selection from second or higher thermal conditioning of thermoplastic composites herein can be regraded to manufacturing and environmental issues such as wax, chemical and other volatiles removal as well as moisture evaporation from samples' surface.

A closer look to the aforementioned graphs reveals similarities irrespective of the wood species considered, especially in case of lower particle content. Furthermore, there it can be seen a linear increase in the thermal stress field developed within the composite specimens with temperature increase.

Little discrepancies can be found with wood species reinforced thermoplastics having a 40 wt.\% weight fraction that revealed smaller thermal stress values due to the higher particle content impeding large specimen dimension expansion, and thus high thermal stress development.

Additionally, in both cases it can be seen that thermal stress fields are crossing around $55{ }^{\circ} \mathrm{C}$ with exception of pine reinforced PP composites. This behaviour was identified within herein wood reinforced thermoplastics and can be sought to hold particularly to the specimens under scrutiny.

\section{Perspectives}

Accounting the huge interest of automotive players on WPCs development, the subject remains under scrutiny.

Wood plastic composites are known both as sustainable and biodegradable materials and redoubtable competitor for green polymer composites out of natural fibres reinforced within organic/inorganic polymer matrices.

In the near future, it is expected to identify automotive components out of WPCs or in combination with these, such as: headliners, sunroof sliders, front and rear door linens, as well as decorative appliances.

Supplementary research is needed on WPCs material properties, including mechanical, acoustics, thermophysical or dynamic mechanical accounting for various wood content and/or species.

A niche can be easily identified in the direction of WPCs out of recycled components, especially in terms of thermoplastic polymer matrix. Nonetheless, despite the high number of articles approaching the natural constitutive pyrolysis and thermal stability, both reinforcements and matrices related, there are numerous potential subject to be approached.

In addition, specimen degradation under extreme environmental conditions remains a hot subject to be tackled accounting its importance on automotive components life time cycle.

From a manufacturing perspective, automotive producers were adapting their production lines and processes to adapt to natural/green reinforcements or combinations of these.

Novel architectures emerged naturally such is the one developed within Draexlmeier Group based on a combination between kenaf fibres and PP mat mixed into a cross-layering process [23]. The innovation moved further on displaying a translucent decorative film onto the heated combination by lamination process. The outcome panels were proven to comply with the sustainable criteria imposed for mass production in addition to the demands concerning the lightweight design and safety, surface feel and usability.

Lightweight strategies to achieve potential weight saving up to $50 \%$ and beyond for increased number of automotive components may consider the herein composites as candidates for their structures especially if economy to cost come as an imposed strategy of development.

Among the weight reducing strategies adopted by OEMs to minimize weight in automobiles can be mentioned the deployment of light weight materials, revision of manufacturing phases/processes, optimization of existing designs, irrelevant content/features removing and parts/systems resizing.

\section{Conclusions}


Thermal degradation and stability of several wood species reinforced in polypropylene matrix under two different content, 10 wt. $\%$ and 40 wt. $\%$ respectively, was monitored and debated.

Thermal degradation of WPCs considered reveal similarities in characteristics irrespective of their wood particle content. Little discrepancies on the degradation temperatures $\left(\mathrm{T}_{\max }\right)$ with increase in the wood content were accounted.

Char formation is greatly influenced by the wood content, increasing along with it from $10 \%$ to $35 \%$ or higher. Thus, final decomposition temperature should be set to a value higher than $650^{\circ} \mathrm{C}$.

With respect to the WPCs thermal stability, an increase on the wood content lead to small samples expansivities, more pronounced with agglomerate, oak and pine specimens, from $20 \%$ up to $50 \%$ and more. The higher the content of wood reinforcement content, the enhanced thermal stability of the specimens. This property is particular important during sun exposure of wood particle reinforced thermoplastic polymer composites.

With respect to thermal stresses developed within composite specimens, a linear increase with temperature was identified to hold irrespective of wood species. Little discrepancies can be regarded with respect of the overall thermal stress field with increase of the wood particle content, from 10 wt. $\%$ up to 40 wt.\%.

An optimization procedure to identify the wood content that enables enhanced thermal stability and diminished char formation can be approached inherently as a subsequent research step.

Other thermoplastic polymers can be further accounted as matrix material in addition of considering the wood particle reinforcement as a component within a hybrid combination with other materials prone to be deployed as engineering materials.

\section{References}

1. A. Ashori, Bioresource Technology 99 (11), 46614667 (2008).

2. Qiang Yuan, Donglyang Wu, J. Gotama and S. Bateman, Journal of Thermoplastic Composite Materials 21 (3), 195-208 (2008).

3. L. Sobczak, R. W. Lang and A. Haider, Composites Science and Technology 72 (5), 550-557 (2012).

4. M. Valente, F. Sarasini, F. Marra, J. Tirillò and G. Pulci, Composites Part A: Applied Science and Manufacturing 42 (6), 649-657 (2011).

5. L. Dányádi, T. Janecska, Z. Szabó, G. Nagy, J. Móczó and B. Pukánszky, Composites Science and Technology 67 (13), 2838-2846 (2007).

6. L. Dányádi, J. Móczó and B. Pukánszky, Composites Part A: Applied Science and Manufacturing 41 (2), 199-206 (2010).

7. H. Matini Behzad, A. Ashori, A. Tarmian and M. Tajvidi, Construction and Building Materials 35 (0), 246250 (2012).
8. R. Csizmadia, G. Faludi, K. Renner, J. Móczó and B. Pukánszky, Composites Part A: Applied Science and Manufacturing 53 (0), 46-53 (2013).

9. W. V. Srubar Iii, S. Pilla, Z. C. Wright, C. A. Ryan, J. P. Greene, C. W. Frank and S. L. Billington, Composites Science and Technology 72 (6), 708-715 (2012). 
10. L. Wei, A. G. McDonald, C. Freitag and J. J. Morrell, Polymer Degradation and Stability 98 (7), 13481361 (2013).

11. F. A. Soares and S. M. B. Nachtigall, Polymer Testing 32 (4), 640-646 (2013).

12. J. S. Fabiyi and A. G. McDonald, Composites Part A: Applied Science and Manufacturing 41 (10), 14341440 (2010).

13. A. Nourbakhsh, A. Karegarfard, A. Ashori and A. Nourbakhsh, Journal of Thermoplastic Composite Materials 23 (2), 169-174 (2010).

14. R. Bouza, C. Marco, M. Naffakh, L. Barral and G. Ellis, Composites Part A: Applied Science and Manufacturing 42 (8), 935-949 (2011).

15. S. Jeamtrakull, A. Kositchaiyong, T. Markpin, V. Rosarpitak and N. Sombatsompop, Composites Part B: Engineering 43 (7), 2721-2729 (2012).

16. A. Thumm and A. R. Dickson, Composites Part A: Applied Science and Manufacturing 46 (0), 45-52 (2013). 17. S. Singh, A. K. Mohanty and M. Misra, Composites Part A: Applied Science and Manufacturing 41 (2), 304312 (2010).

18. H. S. Yang, M. P. Wolcott, H. S. Kim and H. J. Kim, J Therm Anal Calorim 82 (1), 157-160 (2005).

19. M. Chaharmahali, J. Mirbagheri, M. Tajvidi, S. K. Najafi and Y. Mirbagheri, Journal of Reinforced Plastics and Composites 29 (2), 310-319 (2010).

20. Pengfei Niu, Baoying Liu, Xiaoming Wei, Xiaojun Wang and Jie Yang, Journal of Reinforced Plastics and Composites 30 (1), 36-44 (2011).

21. Y. H. Cui, J. Tao, B. Noruziaan, M. Cheung and S. Lee, Journal of Reinforced Plastics and Composites 29 (2), 278-289 (2010).

22. P. Maryandyshev, A. Chernov, V. Lyobov, G. Trouve, A. Brillard, J. Brilhac, Journal of Thermal Analysis and Calorimetry 122, 963-973 (2014).

23. I. Schmiedel, G. Barfuss, T. Nickel and L. Pfeufer, ATZ worldwide 116, 20-23 (2014). 